\title{
EL NEGOCIO DE LOS ARRENDAMIENTOS \\ DE RENTAS SEÑORIALES: \\ EXAMEN DE UN LIBRO DE CUENTAS
}

GASPAR FELIU

Universidad de Barcelona

\section{INTRODUCCION}

Es bien sabido que la mayor parte de los tenedores de las diversas modalidades de rentas señoriales no obtenían sus ingresos del cobro directo de sus derechos, sino que preferían arrendar éstos y obtener a cambio una cantidad alzada ', de forma que a través de los arrendamientos una parte de las exacciones señoriales no iba a parar a mano de los señores, sino a la de los perceptores de los arriendos; con ello, como afirma Pierre Vilar ${ }^{2}$, se posibilitaba una acumulación de capitales procedentes de la tierra y con ciertas posibilidades de ser invertidos en empresas comerciales y aun industriales. El tema encierra, sin embargo, dos interrogantes de importancia: ¿cuál era el beneficio que podía obtenerse de esta actividad?, y ¿cuál era el valor realmente pagado por los vasallos sujetos a prestaciones señoriales? Preguntas imposibles de responder sin largas series de cuentas de arrendatarios, que son sumamente escasas; Vi$\operatorname{lar}^{3}$ advierte que no hay esperanza de cifrarlas, y me guardaré mucho de desmentirle. Sin embargo, la rotunda afirmación del maestro francés y la escasez de cuentas disponibles quizá han hecho abandonar con demasiada rapidez el campo; aunque no se pueda dar una respuesta cifrada, creo que sí se pueden sacar enseñanzas del examen del funcionamiento de casos concretos.

Las fuentes, por desgracia, escasean; en Barcelona (pero sin haber llevado a cabo una investigación a fondo) no he podido localizar más que dos, ambas en el Instituto Municipal de Historia, procedentes de los fondos de casas comerciales en bancarrota ${ }^{4}$. En una de estas contabilidades aparecen mezcladas

' Para los diezmos y su forma de recolección puede verse el reciente estudio de Canales (1982).

? Vilar (1962), vol. 111, pp. 484-485. Véase también Torras (1979).

3 Vilar (1962), vol. III, pp. 436-437.

+ Es posible que se pudiese reconstruir el funcionamiento de otros arrendamientos a través de la documentación de la casa Cortadellas, que se conserva en parte en el Archivo Provincial de Tarragona. Los Cortadellas, a través de las numerosas sociedades que animaron, fueron, sin duda, los más importantes arrendatarios de derechos señoriales a fina- 
con las cuentas del arrendamiento anotaciones de otros negocios de la misma compañía, por lo que resulta prácticamente inutilizable; la otra, que, como se verá, presenta también complejos problemas de interpretación contable, es el objeto del presente trabajo.

\section{BASE DOCUMENTAL}

Se trata de un libro de cuentas ${ }^{5}$ de diversas compañias dedicadas básicamente al arrendamiento de derechos señoriales en el bajo Ebro y en Aragón, entre los años 1764 y $1773^{\circ}$, en todas las cuales participaba, y posiblemente era elemento básico, Josep García i Alegre, de Altafulla ${ }^{7}$. Las cuentas corresponden a los siguientes arrendamientos:

a) El arrendamiento de Ulldecona los años 1764-1767, obtenido por 3.225 ps. $^{8}$ al año por una compañía formada, a partes iguales, por Jaume García i Molas ${ }^{9}$, Josep Bover y Josep García i Alegre.

b) El arrendamiento de Ulldecona y Amposta ${ }^{10}$ los años 1767 a 1770 , por el que pagaron 3.425 ps. al año los socios Josep García, con una participación de 6/19; Jaume García y Josep Bover, con 4/19 cada uno; Manuel García, con 3/19, y Josep Llagostera, con 2/19".

c) El arrendamiento de Bujaraloz los años 1767 a 1769 , cerrado en $2.249,1$ ps. al año por una compañía con la misma composición y reparto que la del arrendamiento de Ulldecona de 1767 a 1770.

les del siglo xvili y principios del siglo xix. Sobre esta familia y sus actividades pueden verse Fontana (1974), Torras (1979), Sales (1983).

Instituto Municipal de Historia de Barcelona, «Fons Comercial. B-191». En la portada, en parte casi borrada, puede leerse: «Llibre de tots los pasaments de comptes», y añadido de mano posterior: «de Ferrer y García a los consortes Grau. F. n. 70 ».

- Las liquidaciones y algunas anotaciones son, sin embargo, de fechas bastante posteriores.

' Por estos mismos años, o los inmediatamente posteriores, García i Alegre se había ocupado también de las obras de desecamiento del estanque de Tamarit, según un pleito de 1782 citado por Vilar (1962), vol. III, p. 213.

" La contabilidad está llevada básicamente en moneda de cuenta catalana, pero hay también páginas en moneda de cuenta aragonesa y otras en pesos duros. He unificado todas las cuentas a pesos duros y sus decimales (abreviado en adelante ps.), de acuerdo con las equivalencias usuales en la época: 0,714 ps. por libra catalana y 1,234 ps. por libra aragonesa.

${ }^{9}$ En la certificación de finiquito de las cuentas aparece en el texto como Jaume Palau y Molas, pero firma Jaume García, y así aparece en todas las otras ocasiones.

${ }_{10}$ Es posible que también el anterior arrendamiento de 1764 a 1766 se refiriese a Ulldecona y Amposta; el valor ofrecido en ambas subastas no es muy diferente: 3.425 ps./ año contra 3.225; ante la duda hemos preferido, sin embargo, no integrar las series.

"Josep Llagostera se retiró de este arrendamiento en 1770 y su parte fue repartida entre el resto de los socios. Sin embargo, Llagostera empezó a participar el mismo año en el arrendamiento de Calatayud. 
d) $\mathrm{El}$ arrendamiento de Barbastro de 1767 a 1769 , por el que pagó $1.298,48$ ps. la misma sociedad ${ }^{12}$.

e) El arrendamiento de las bailías de Miravet (8.381,33 ps. año), de Caspe $(4.257,3$ ps. año) y de Calatayud ( 3.702 ps. año) para los años 1770 1773 por una compañía formada por Josep García, con una participación de 5/15; Josep Bover, con 3/15; Jaume García, con 3/15; el doctor José Josa, con 2/15; el señor Tomás Vives, con $1 / 15$; el quinceavo restante fue, en Miravet y Caspe, para Pere Joan Ferrer y, en Calatayud, para Josep Llagostera, aunque de la encomienda de Calatayud solamente constan las cuentas de los años $1770-1773^{13}$.

Por desgracia, ignoro qué derechos señoriales correspondían a cada uno de los arrendamientos, ya que no he podido hallar la taba de los mismos, ni siquiera tabas de otros años pertenecientes al mismo señorío; en cuanto a éstos, aunque no se exprese, parecen pertenecer todos ellos a la Orden Militar de San Juan de Jerusalén ${ }^{14}$.

En el cuaderno podemos distinguir tres grandes partes ${ }^{15}$. Al inicio hay una serie de liquidaciones por partida doble entre Josep García i Alegre, que hace constar y cobra su encargo de llevar los libros y acaba con una liquidación a sí mismo ${ }^{16}$, y diversos socios, fechado todo ello en 1772 . En el debe de estas liquidaciones figuran principalmente los adeudos de García por las ganancias de los diversos arrendamientos y algunas cantidades que García había recibido de ellos o les adeudaba de negocios anteriores; en el haber, mucho más complejo, constan anticipos, pagos hechos en nombre de los socios, cantidades de productos retirados por éstos y gastos de los arrendamientos que no se habían hecho constar en las cuentas específicas, así como deudas no cobradas, de las

${ }^{12}$ Estos datos constan en un documento de liquidación de cuentas firmado por todos los socios a excepción de Josep Llagostera.

${ }_{13}$ Por una serie de anotaciones y liquidaciones de cuentas sabemos de otros arrenda mientos y negocios diversos en los que participan algunos de los socios, a veces sólo García y Bover. Se trata de los arrendamientos de la bailía de Miravet de 1774 a 1777, que se saldó con pérdidas importantes; de la encomienda de la Segarra, de Huesca y Tavernas, y de Vinyoles, todos ellos posteriores a 1772 , sin que podamos precisar más, y de diversos negocios: ventas de bacalao, sedas y aguardiente; participación en «motas» de barcas, en un caso al menos para un viaje a Galicia; participación en la fundación de una casa de comercio en la Habana promovida por la razón social «Prat, Martí, Baldrich y Fuster", de Barcelona. Los datos de todos estos negocios son bastante incompletos, pero sabemos que las 2.000 libras ( 1.428 ps.) de mota entregadas al patrón Gabriel Colom en aguardiente y otros géneros dieron un beneficio de 253,47 pesos, o sea, un 17,77 por 100 , y que la instalación de la casa de comercio en la Habana debió dar también buenos beneficios, aunque solamente encontramos contabilizado un «tercer repartimiento» cercano al 10 por 100 del capital invertido.

14 También llamada Orden del Hospital o de San Juan de Malta.

${ }_{15}$ El libro de cuentas no está foliado, y aproximadamente la mitad de él está en blanco.

${ }^{16}$ En páginas encabezadas por «Deu... Acredito», o bien «Deu... Haver» y «Deu Josep Garcia â ell mateix», en el último caso. 
cuales se cargaba a los socios la parte proporcional, que sería abonada al producirse el cobro. La parte final contiene también nuevas liquidaciones, fechadas a partir de 1781 , y que sólo interesan a Josep García i Alegre y a Josep Bover, seguidas de diferentes certificaciones de liquidaciones parciales y notas sobre deudas. La parte más interesante es, sin embargo, el cuerpo central, en el que figuran con detalle, y por el sistema de cargo y data ${ }^{17}$, las cuentas de los arrendamientos reseñados.

Las diversas contabilidades no son, por desgracia, todo lo homogéneas que desearíamos: en unos casos se trata de simples resúmenes de ingresos, gastos y beneficios; en otros se especifican con mayor o menor detalle los frutos recogidos, los productos elaborados a partir de dichos frutos, con los gastos ocasionados por dicha transformación, y el producto de las ventas.

Finalmente, en el caso de la Castellanía de Amposta o Bailía de Miravet ${ }^{18}$, se trata de las cuentas de liquidaciones de los colectores que la compañía tenía en los diferentes pueblos; otros datos no aparecen en las cuentas, pero pueden ser deducidos de las liquidaciones ${ }^{19}$. Pasar de estas cuentas a los ingresos y gastos de los arrendamientos obliga a una reordenación y reinterpretación de las partidas que nos enfrenta a más de una laguna. De los problemas que se nos han planteado y de cómo hemos intentado obviarlos trataremos al abordar cada caso concreto.

\section{ORGANIZACION DE LA EXACCION SEÑORIAL}

Sobre la forma de operar de estas compañías encontramos algunas indicaciones en las cuentas. A menudo, los socios no solamente involucraban capital, sino que tomaban parte activa en la vigilancia de la recolección de los frutos; con este fin se buscaba interesar en el negocio a alguna persona de la zona arrendada; así vemos que en los arrendamientos obtenidos en 1770 participaban el doctor José Josa, de Samper, población aragonesa que formaba parte de la bailía de Caspe, y Pere Joan Ferrer, de Batea, de la bailía de Miravet. Estos socios locales, buenos conocedores de la población y de los derechos a

"Sobre el sistema de contabilidad por «cargo y data» puede verse Hernández Esteve (1982).

18 Por Castellanía de Amposta se entiende, a partir de la disolución de la Orden del Temple y la reorganización de la del Hospital, tanto el conjunto de territorios hospitalarios en Áragón, la zona catalana al sur del Ebro y el País Valencià como la antigua bailía de Miravet, que pasó a formar parte de las rentas directas del castellán de Amposta; en nuestro caso se trata de esta antigua bailía. Para evitar equívocos utilizaremos en adelante la denominación de bailía de Miravet.

19 Se trata de cobros o pagos no contabilizados por los colectores por haber sido hechos directamente por el administrador principal, 
pagar, podían, además, desempeñar un papel más activo: mientras el doctor Josa no parece haber sido más que un consejero, Ferrer actuó como colector.

La gestión y buena marcha de los arrendamientos exigían también la participación de asesores y escribanos ${ }^{20}$; con todo, el personaje básico para la buena marcha de la recolección de los derechos y frutos era el colector, que podía ser único para toda el área arrendada o bien ocuparse de una zona más concreta. A menudo el cargo recaía en un socio, caso del antes nombrado Pere Joan Ferrer, a quien vemos actuando en la bailía de Miravet de 1770 a 1773, o de Josep Bover, quien parece haber realizado una especie de supervisión general sobre los colectores de dicha bailía los mismos años ${ }^{21}$; de Jaume García, quien actuó el mismo período en Caspe, o del mismo Josep García i Alegre, que ejerció el cargo en Ulldecona durante el arrendamiento de 1764 a 1766. Otras veces encontramos como colectores a «especialistas», como Bernat Fuster, que lo fue del arrendamiento de Ulldecona de 1767 a 1770 y de los pueblos de Benissanet y Ginestar, y probablemente también de Rasquera y Miravet, de 1770 a $1773^{22}$.

Solamente en dos casos, en Caspe y en Benissanet, el colector fue dotado de una casa, cuyo alquiler, gastos de acondicionamiento y de manutención figuran en las cuentas, aunque en el de Caspe no existe partida de salario del colector, posiblemente embebida en el gasto de la casa. En los demás casos, los colectores eran posiblemente residentes del lugar donde ejercían su oficio $y$, por esta razón, falta el importante capítulo del gasto de casa.

Por debajo de los colectores quedan los nuncios o corredores, a los que sólo en un caso (Batea) se pone también casa, aunque más humilde y sin pagar más que el arrendamiento ${ }^{23}$. Más interesante es ver cómo para estos oficios se busca a veces la colaboración de las autoridades locales, que de esta forma ponen la violencia legal de que son depositarios al servicio de los arrendatarios

${ }^{20}$ Aparecen también pagos a notarios, pero su participación se reducía seguramente a redactar y oficializar las escrituras de arrendamiento, fianzas y, quizá, constitución de las compañías.

${ }^{21}$ En la liquidación de cuentas de 1881 se le reconocen 99,96 ps. por su salario de colector en la bailia. Puesto que le vemos recibir repetidamente cantidades y productos de los colectores, nos inclinamos a creer que ejerció esta supervisión general. Otra posibilidad es que se ocupase simplemente de la colecta de los pueblos de Rasquera y Miravet, en las cuentas de los cuales está en blanco el nombre del colector.

${ }_{22}$ Para su cometido le fue alquilada a Bernat Fuster una casa en Benissanet y recibió un salario de 99,96 ps., prácticamente el triple de lo que cobraban los colectores de un solo lugar. En cambio, en las cuentas de Ginestar, de Rasquera y de Miravet no aparece ninguna partida de pago por colectoría y, en su encabezamiento, el nombre del colector fue dejado en blanco; sólo en el primer año de Ginestar una mano distinta anotó «Fuster», indicación que creemos válida para todos estos pueblos, por otra parte próximos a Benissanet.

${ }^{23}$ En las cuentas de Batea de 1770 aparece una partida de 16,06 ps. por el salario del corredor y otra de 6 ps. por el alquiler de la casa del nuncio; en 1771, en vez de casa del nuncio se habla del corredor, y lo mismo sucede en 1772 . 
de los derechos señoriales ${ }^{24}$; sin duda, era ésta una obligación de los bailes, expresamente reconocida en las tabas de los arrendamientos, pero aún menos cabe dudar de que aquéllos cumplían con más empeño su obligación si se les recompensaba con un sobresueldo. Otras veces, sin embargo, encontramos pagos a corredores o nuncios sin que conste que ostenten cargo local alguno. Aparecen también, finalmente, en Caspe los alfarrazadores, oficio típicamente aragonés; los alfarrazadores calculaban la cosecha antes de la siega y, si su estimación era aceptada por las partes, servía de base para el cálculo de la cantidad a entregar como diezmo ${ }^{25}$. Aparte de este personal que podemos considerar como fijo, y al que habría que añadir en algunos casos los molineros, existían siempre otros gastos por jornales eventuales de acarreo, limpieza de los granos, obtención del vino, etc., así como el alquiler de algunas acémilas. Además, es posible que en la manutención de las casas o en el pago de algunos jornales se gastasen algunos diezmos menores (hortalizas, almendras, etc.) que solamente aparecen en las cuentas algunos años; no podemos hacer en este caso más que señalar el problema.

Si de la organización pasamos a la forma de actuar encontramos también notables diferencias según los productos e incluso, para un mismo producto, según los lugares y los años. Por regla general, solamente los cereales, las frutas y legumbres y los corderos eran vendidos sin manipulación alguna, aunque en un caso queda la duda de si lo que se vende es trigo o harina (muy probablemente trigo) ${ }^{26} \mathrm{y}$, en otro, los corderos fueron posiblemente retenidos durante un año para su engorde ${ }^{27}$. Los demás productos acostumbran a ser transformados o bien utilizados como materia prima para otras actividades. Aparte de los casos ya mencionados, esto afecta sin excepción a la vendimia y las aceitunas, que son siempre vendidas en forma de vino o aguardiente $v$ de aceite. Otros productos son transformados sólo a veces, como el cáñamo, del que en una ocasión se hicieron cuerdas por cuenta de la compañía arrendado-

${ }^{24}$ Encontramos expresamente partidas bajo los epígrafes «al vaile (sic) de Batea por su salario" y "al baile de La Puebla por su salario de correduría» en las cuentas de Batea de $1770 \mathrm{y}$, de forma similar, en las de los años sucesivos.

${ }^{25}$ El sistema tenía para los señores la ventaja de no haber de recorrer los campos o las eras para recoger el diezmo y de evitar los fraudes; para los campesinos, la ventaja estaba en poder retirar las gavillas o el trigo de las eras en el momento que les pareciese oportuno. Todavía en los años sesenta he conocido a los que podríamos considerar como últimos representantes de esta profesión: la compañía Canal de Urgel, S. A., que cobraba en especie los cánones del agua sobre algunas fincas (generalmente al noveno, o sea, una novena parte de la cosecha), mantenía unos denominados guardas estadísticos que realizaban estimaciones avanzadas de las diferentes cosechas, y que tenían fama de permitirse unos márgenes de error muy pequeños.

${ }^{26}$ Caspe; véase infra.

${ }^{27}$ Así interpreto unas anotaciones en el cargo de Benissanet de 1773, donde, tras una partida "por los corderos de toda la Castellanía de 72 y de 73 ", aparece otra "por la ganancia en dichosm. 
$\mathrm{ra}^{28}$, o la hoja de morera, en ocasiones vendida y otras utilizada como base para acabar produciendo hilo de seda ${ }^{29}$. A estas transformaciones podríamos asimilar la utilización de parte de la cebada o avena obtenida para la alimentación de las mulas que movían las prensas de aceite.

Si los arrendatarios se ocupaban a menudo de la transformación de los productos obtenidos, por regla general se desentendían de su comercialización, que quedaba en manos de negociantes (algunos de los cuales aparecen repetidamente), quienes recogían los productos en los pueblos; la excepción es el aguardiente, que a menudo era llevado a Reus. De hecho, otros intentos de comercialización no parecen haberse saldado con éxito: no hay mención en las cuentas de que fuese liquidada la partida de cuerdas entregada a un arriero para que la vendiese a cuenta de la compañía, y un cargamento de trigo llevado el 1773 al Camp de Tarragona para su venta obtuvo un precio inferior al de algunas cantidades vendidas directamente y hubo de soportar unos gastos que ascendieron a un 25 por 100 del precio final ${ }^{30}$. En algún caso, sin embargo, parece que algunos de los socios (principalmente García i Alegre o Bover) se hicieron cargo de algunos productos, sobre todo aguardiente (los «compraron» a la sociedad de arrendatarios), y los comercializaron por su cuenta.

\section{EL NEGOCIO DE LOS ARRENDAMIENTOS SEÑORIALES}

El cálculo tanto del beneficio obtenido por los arrendatarios como del valor de las exacciones realizadas sobre los vasallos presenta toda clase de dificultades, que solamente pueden ser obviadas señalando de entrada que no pretendemos obtener más que indicaciones groseras con una representatividad muy limitada; sin ser mucho, parece mejor que la nada actual sobre el tema.

Por lo que respecta a los beneficios obtenidos por los arrendatarios, indicaremos solamente que, aunque nos interesaremos por los beneficios obtenidos por las diferentes compañías, los socios más activos podían obtener ganancias extras de su dedicación como colectores o contables o de la comercialización particular de los frutos ${ }^{31}$. Más problemas plantea el cálculo del valor extraído del conjunto de los vasallos, necesario para comprender el peso del régimen

28 Ulldecona, arrendamiento de 1767 a 1770 .

29 En algún caso, como en Benissanet, figura en el cargo «seda» o «seda y aldúcar", pero la data no deja lugar a dudas de que lo originariamente recibido era hoja de morera, puesto que figuran partidas de compra de (más) hoja de morera, leña y jornales de hila. doras.

30 Benissanet, 1773.

" En la liquidación de cuentas de 1772 correspondió a Josep García i Alegre $5.241,44$ ps. ( $\sin$ contar las deudas pendientes), de los que 834,66 ps. (16 por 100) provenían de su actuación como colector y escribano. 
feudal. Nuestra intención es comparar el valor de lo realmente pagado por los vasallos con el montante de la subasta; para ello es necesario cifrar dos cantidades: el valor añadido por las transformaciones industriales, que ha de ser deducido de los ingresos finales, y el valor de los productos obtenidos pero que no aparecen en las cuentas, que ha de adicionarse a dichos ingresos. Estos productos sin reflejo contable eran seguramente utilizados para el pago de jornales o pequeños trabajos, o bien consumidos tanto por el colector y su casa como por los animales; el caso de la cebada consumida en la almazara de el Pinell es el más claramente documentado, pero, sin duda, la cantidad consumida fue mayor: ya hemos hablado de los diezmos de hortalizas o frutos secos, pero seguramente habría que añadir el trigo, vino y aceite consumidos en la casa de los colectores, así como la cebada u otros cereales inferiores gastados en la alimentación de los animales de que seguramente disponía el colector.

Resulta imposible caicular tanto la disminución de valor que representa el hecho de que el arrendatario recibiese los productos en bruto, y a menudo en el campo, como el incremento que se experimentaría si no hubiese existido consumo interno. Para intentar un acercamiento, siquiera mínimo, he acudido a una convención: actuar como si el valor añadido se equilibrase con el consumo interno no contabilizable más los gastos realizados para obtener dicho valor añadido. Llamaremos al resultado "valor en origen» $\left(V_{o}\right)^{32}$, y puesto que si queremos utilizarlo como indicador generalizado deberemos compararlo con el precio obtenido por el señor en la subasta, calcularemos también este índice en porcentaje. Dividiremos el estudio de las diferentes compañias arrendatarias en dos grandes apartados: el arrendamiento de la bailía de Miravet, para la que tenemos cuentas más completas y más complejas, que estudiaremos en segundo lugar, y el resto, que pasamos a examinar a continuación ${ }^{33}$.

\subsection{Los arrendamientos menores}

He reunido bajo este epígrafe el estudio de los arrendamientos de Ulldecona, Ulldecona y Amposta, Bujaraloz y Barbastro, de todos los cuales la libreta nos ha conservado solamente una contabilidad muy sucinta.

${ }^{32}$ Descontamos, por tanto, de la suma de ingresos los gastos de recogida, transporte, molienda, transformación, etc., que aparecen en la data, así como el valor de otros arrendamientos o ingresos no pagados por los particulares (hierbas), si los hay.

${ }^{33}$ No incluimos el arrendamiento de Calatayud de 1770-1773, puesto que sólo constan datos de 1770-1771; por otra parte, los datos de que disponemos parecen harto sospechosos: las cuentas de 1771 repiten casi idénticamente las de 1770 (cantidades recogidas, precios, cantidades vendidas a cada precio); solamente en el vino y los corderos hay diferencias. Además, la cantidad que se desprende de estas cuentas es muy superior a la que le es reconocida a Bover en la liquidación de cuentas de 1781. Por todo ello hemos prescindido de este arrendamiento. 
De la primera de las compañías formadas, la del arrendamiento de Ulldecona de 1764 a 1766, sabemos muy poco: en el cargo figura solamente el total de frutos de cada año, con especificación aparte de algunas partidas de aceite; la data es algo más explícita y nos permite conocer el valor del arrendamiento, al que se hallan añadidos otros dos pequeños arrendamientos, los gastos de personal, los gastos provocados por la recolección de los frutos y el montante de la deuda pendiente. Los datos pueden verse en el cuadro 1.

\section{CUADRO 1}

Arrendamiento de Ulldecona de 1764 a 1766

\begin{tabular}{|c|c|c|c|c|}
\hline & INGRESOS 34 & & & \\
\hline 1764 & $\begin{array}{llll}\text { Frutos } & \ldots & \ldots & \ldots\end{array}$ & $5.323,46$ & & \\
\hline 1765 & Frutos, excepto aceite $\ldots \ldots \ldots$ & 5.181 .75 & & \\
\hline 1765 & 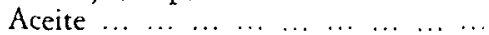 & $1.450,00$ & & \\
\hline 1766 & $\begin{array}{lllllllll}\text { Frutos } & \ldots & \ldots & \ldots & \ldots & \ldots & \ldots & \ldots & \ldots\end{array}$ & $4.725,25$ & & \\
\hline \multirow[t]{11}{*}{1766} & $\begin{array}{lllllllllll}\text { Aceite } & \ldots & \ldots & \ldots & \ldots & \ldots & \ldots & \ldots & \ldots & \ldots\end{array}$ & $1.214,29$ & $17.894,50$ & \\
\hline & $\begin{array}{lllllll}\text { Cabros pendientes } & \ldots & \ldots & \ldots & \ldots & \ldots\end{array}$ & 216,85 & & $18.111,35$ \\
\hline & GASTOS & & & \\
\hline & $\begin{array}{llllllll}\text { Arrendamientos } & \ldots & \ldots & \ldots & \ldots & \ldots & \ldots\end{array}$ & $9.675,00$ & & \\
\hline & $\begin{array}{lllll}\text { Otros } \text { arrendamientos } & \ldots & \ldots & \ldots & \ldots\end{array}$ & 37,00 & & \\
\hline & $\begin{array}{lllllllll}\text { Salarios } & \ldots & \ldots & \ldots & \ldots & \ldots & \ldots & \ldots & \ldots\end{array}$ & 535,00 & & \\
\hline & Recolección de frutos $\ldots \ldots \ldots$ & $3.002,86$ & $13.249,86$ & \\
\hline & BENEFICIO & & $4.644,64$ & $4.861,49$ \\
\hline & $\begin{array}{llllllll}\% \text { beneficio } & 35 & \ldots & \ldots & \ldots & \ldots & \ldots & \ldots\end{array}$ & & 35,05 & 36,39 \\
\hline & $\begin{array}{lllllllllll}V_{0} & -1 & \ldots & \ldots & \ldots & \ldots & \ldots & \ldots & \ldots & \ldots & \ldots\end{array}$ & & $14.891,64$ & $15.108,49$ \\
\hline & 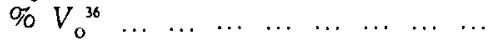 & & 53,92 & 56,16 \\
\hline
\end{tabular}

Las cuentas del arrendamiento de Ulldecona y Amposta de 1767 a 1770 son bastante más completas; encontramos en ellas una importante partida de gastos realizados para obtener el arrendamiento ${ }^{37}$, así como un fuerte incremento de los arrendamientos secundarios (fincas, casas mejor diezmeras). El principal problema que plantean reside en el hecho de que una parte no especificada del cáñamo fue transformada en cuerdas, pero si bien los gastos de transformación figuran en la data ${ }^{38}$, en el cargo sólo aparece una parte de los

${ }^{34}$ Gastos e ingresos vienen a equivaler a las partidas de data y cargo de la contabilidad original.

${ }_{35} 100$ (Ingresos - gastos) / gastos.

${ }^{36}[100$ (Ingresos - gastos de recolección) / arrendamiento] -100 .

33 «Per regalos, ques feren, per lográr lo present Arrendament y Viatges y salari del acte de puja.»

${ }^{38}$ En la data figuran como gastos de transporte del cáñamo y de confección de las cuerdas 146 ps., pagados por Josep García i Alegre, pero en las liquidaciones aparece otra partida de 60,58 ps. «per gasto de las cordas». 
ingresos, puesto que falta el importe de las cuerdas entregadas al arriero Jaime Casasús, que éste debía liquidar a la vuelta de su viaje a lugares no especificados, regreso que no había tenido lugar al cerrar las cuentas ${ }^{39}$, de forma que el capítulo de ingresos queda cojo en este punto. Los datos correspondientes figuran en el cuadro 2 .

\section{CUADRO 2}

Arrendamiento de Ulldecona y de Amposta de 1767 a 1770

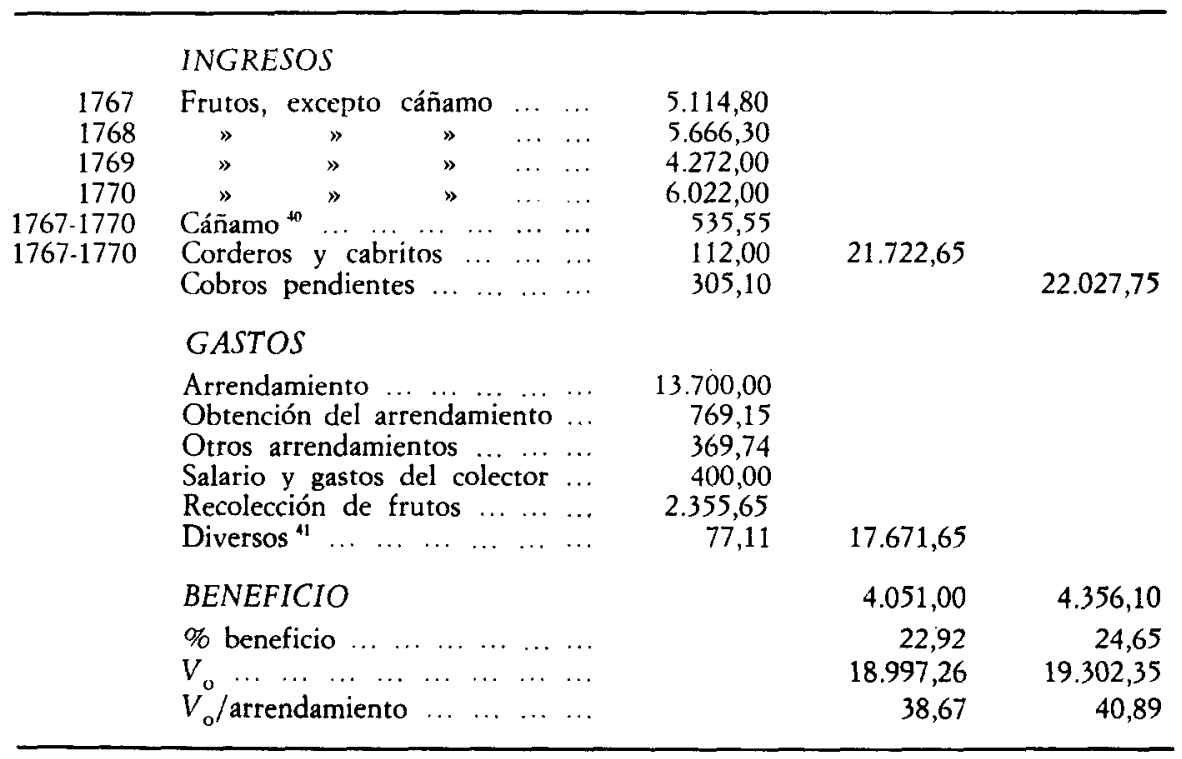

Los arrendamientos de Bujaraloz y de Barbastro, ambos para los años 1767 1769, ofrecen también unos datos muy escuetos: total de los ingresos anuales en el cargo, total de los gastos en la data. Las cifras pueden verse en los cuadros 3 y 4 .

Los arrendamientos de Caspe (1770-1773) ofrecen más datos, pero presentan también un problema de interpretación importante: el trigo aparece bajo la rúbrica «trigo recibido por meses en los molinos», lo que lleva a la

\footnotetext{
${ }^{39}$ "Quan arribia de Viatge, allò que portia se repartiran per iguals parts en los companys."

* Cáñamo vendido, en parte transformado en cuerdas.

${ }^{4}$ Alzado de un plano de la iglesia de Amposta y otros gastos no especificados.
} 
CUADRO 3

Arrendamiento de Bujaraloz de 1767 a 1769

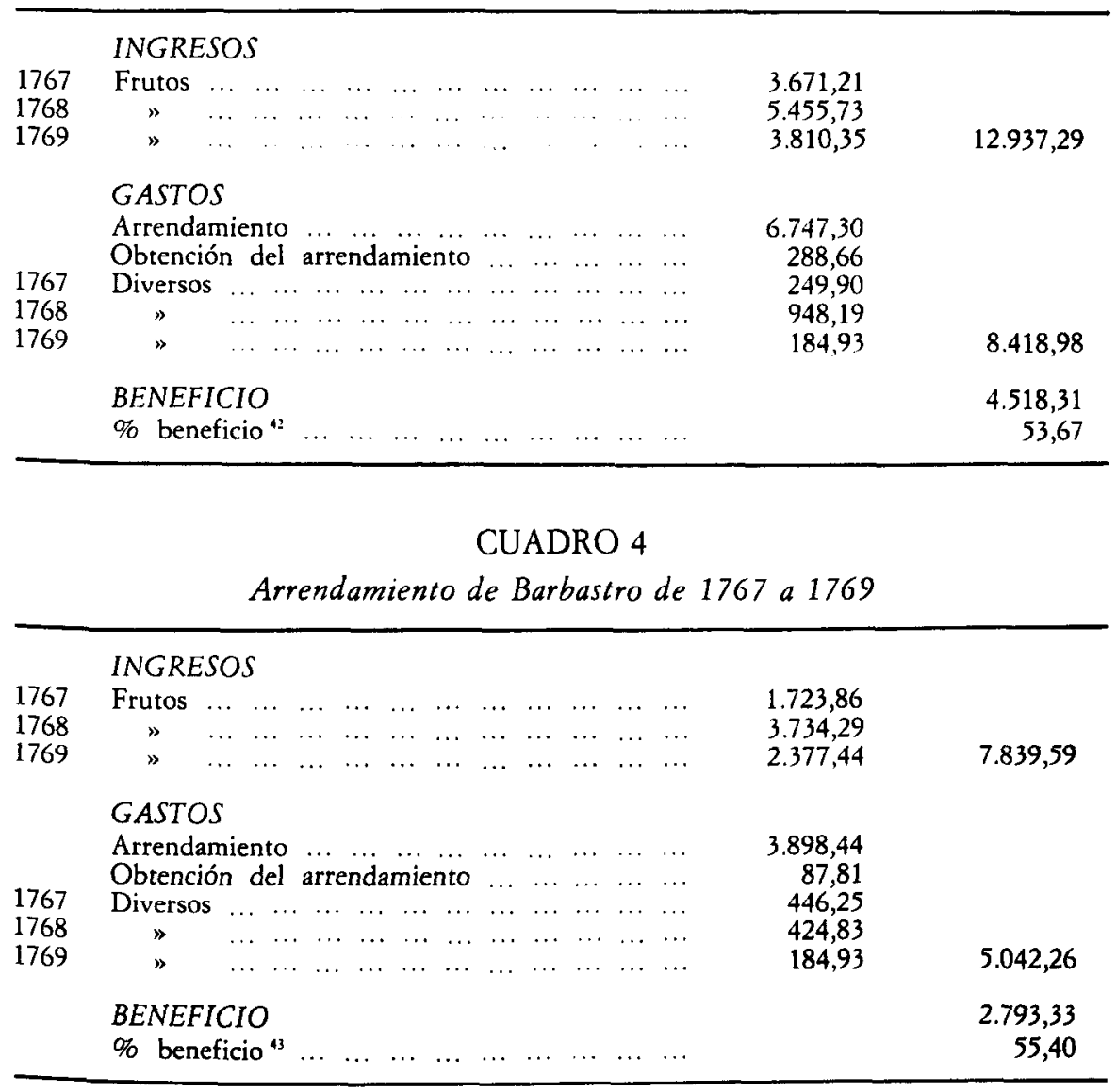

duda de si lo que se valora y vende es trigo o es harina; sin embargo, de la comparación del precio con el obtenido los mismos años en la bailía de Miravet resulta un precio menor en Caspe ${ }^{44}$. Pero entonces faltan los beneficios

${ }^{2}$ Resulta imposible de calcular el $V_{o}$, dado que en la data no hay separación alguna entre los gastos de salarios y los de recolección y transformación, en su caso, de frutos. $\mathrm{Si}$ aceptásemos una proporción entre salarios y gastos de recolección como la que aparece constante en Ulldecona ( 85 por 100 gastos, 15 por 100 salarios), el $V_{o}$ sería $11.761,72$ ps., $y$ su porcentaje, 74,32 .

4" La situación es la misma que la descrita en la nota anterior. Operando de igual forma tendríamos $V_{o} 6.779,58$, y su porcentaje, 73,90 .

" Si las medidas utilizades son las que suponemos (cahiz de 180,4 1. en Caspe, cuarte- 
que cabría esperar del molino harinero, que, en cambio, sí produce gastos ${ }^{45}$. Las cifras y cálculos, dejando aparte estas anomalías, pueden verse en el cuadro 5 .

En conjunto, estos arrendamientos menores ofrecen tasas de beneficio altas, aunque muy variables; el hecho de que las tasas más altas se obtengan de las cuentas menos precisas (Bujaraloz y Barbastro) hace sospechar si el resultado no es debido, al menos en parte, a olvidos en las partidas de gastos; sin embargo, por muy crítico que se sea, parece difícil pensar en un beneficio inferior promedio de los dos arrendamientos de Ulldecona, o sea, de aproximadamente un 30 por 100 .

\subsection{El arrendamiento de la bailia de Miravet}

La documentación correspondiente a la bailía de Miravet es, como queda dicho, mucho más compleja. Para empezar, no se trata de unas cuentas únicas, sino de un conjunto de cuentas de uno o diversos pueblos ${ }^{46}$, mezcladas con anotaciones conjuntas, transporte de algunos productos de un lugar a otro y menciones de cobros no realizados por el colector, sino directamente por «los señores» (posiblemente García i Alegre o alguien en nombre suyo). Por otra parte, la manipulación de productos (obtención de aguardiente, seda, etc.) es mucho más importante y, por si todo ello fuese poco, faltan las cuentas de los años 72 y 73 del pueblo de Corbera y solamente se dispone de una cantidad global, tanto de gastos como de ingresos, para Batea el $1773^{47}$, aparte de unas

ra de Barcelona de 69,518 1. en la bailía), el precio por Hl, habría sido, en 1770 , de 5,47 ps. en Caspe y de 5,75 ps. en Batea. Como únicas explicaciones posibles se me ocurre, o bien que era costumbre vender el trigo en el molino, donde los compradores podian a continuación hacerlo moler o no, o bien que el molinero se había convertido, de hecho, en comprador único. Ninguna de ellas es, desde luego, demasiado satisfactoria.

"5 No es el único caso que aparecen en las cuentas olvidos de este tipo. Los hemos suplido cuando teníamos elementos mínimamente razonables para hacerlo. Estas omisiones influyen, sin duda, en los resultados finales, pero creemos que no de forma significativa.

4 Batea, El Algar y la Pobla de Massaluca, colector Pere Joan Ferrer; Corbera, colector Josep Giner (solamente 1770-1771); Gandesa, colector Josep Soler; Benissanet, colector Bernat Fusté; Pinell, colector Ramón Montagut; Ginestar, colector Fusté; Rasquera (no consta el colector); Miravet (no consta el colector).

${ }^{47}$ Puesto que las cifras globales no sufrían excesivamente por ello, hemos intentado una aproximación a las cifras de Corbera y de Batea. Para Corbera, los ingresos han sido calculados para 1772 y 1773 en base a la participación media del pueblo en los ingresos totales de 1770 y 1771 , y repartida la cantidad en cada partida según el porcentaje representado en los dos años. Los gastos han sido calculados de manera similar, manteniendo sobre los ingresos de cada año el porcentaje que representó la media de 1770 y 1771. En cuanto al reparto entre las diferentes partidas, se han deducido en primer lugar los gastos fijos (gastos de personal) y calculado el resto sobre los porcentajes de gastos de la media 1770-1771, tras haber eliminado, por comparación con 1771, los gastos de elaboración de aguardiente que figuran en las cuentas de 1770. 


\section{CUADRO 5}

Arrendamiento de la bailía de Caspe de 1770 a 1773

\begin{tabular}{|c|c|c|c|c|c|}
\hline & 1770 & 1771 & 1772 & 1773 & Total \\
\hline 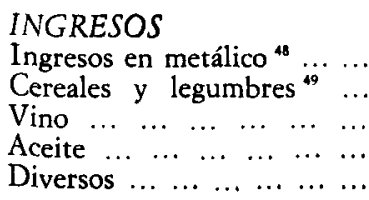 & $\begin{array}{r}644,27 \\
6.438,16 \\
314,67 \\
760,17 \\
62,93\end{array}$ & $\begin{array}{r}694,13 \\
3.531,30 \\
472,38 \\
1.040,83 \\
55,19\end{array}$ & $\begin{array}{r}694,13 \\
4.630,89 \\
331,70 \\
755,51 \\
80,93\end{array}$ & $\begin{array}{r}617,62 \\
4.618,81 \\
180,47 \\
886,57 \\
92,68\end{array}$ & $\begin{array}{r}2.650,15 \\
19.219,16 \\
1.299,22 \\
3.446,08 \\
271,73\end{array}$ \\
\hline Total $\ldots \ldots \ldots$ & $8.240,20$ & $5.793,83$ & $6.493,16$ & $6.396,15$ & $26.906,34$ \\
\hline 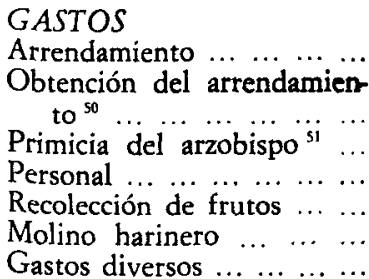 & $\begin{array}{r}4.257,30 \\
31,10 \\
135,74 \\
294,93 \\
238,17 \\
115,01\end{array}$ & $\begin{array}{r}111,06 \\
236,93 \\
78,99 \\
127,35\end{array}$ & $\begin{array}{l}127,10 \\
239,40 \\
140,67 \\
127,35\end{array}$ & $\begin{array}{l}120,00 \\
500,27\end{array}$ & $\begin{array}{r}17.029,20 \\
31,10 \\
493,90 \\
771,26 \\
457,83 \\
369,71 \\
500,27\end{array}$ \\
\hline 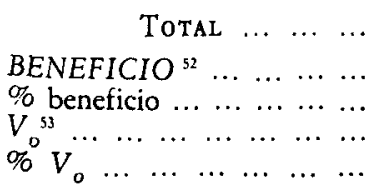 & $5.072,25$ & $4.811,63$ & $4.891,82$ & $4.877,57$ & $\begin{array}{r}19.653,27 \\
7.253,07 \\
36,91 \\
26.200,49 \\
1,54\end{array}$ \\
\hline
\end{tabular}

${ }^{48}$ Censos, peso y romana, arriendo de tres campos y rearriendo del vino y corderos de Chipriona.

${ }_{4}$ Trigo, cebada, avena, centeno, maíz, judías. El trigo viene a valer diez veces más que la cebada o que los otros productos juntos.

${ }^{50} \mathrm{La}$ rúbrica dice "por 4 dozenas de capones y 6 carneros olivas y portes en Zaragoza»; la hemos asimilado a los gastos de obtención del arrendamiento, aunque posiblemente éstos fueron superiores.

st Una cuarta parte de la primicia pertenecía al arzobispo de Zaragoza. La cantidad igual puede ser considerada como un gasto más que deducida de los ingresos. La hemos computado como gasto a efectos de no modificar el conjunto de ingresos obtenidos. Para el cálculo del beneficio sería preferible deducirla de los ingresos, puesto que se trataba de una cantidad con la que ya se sabía que no se podía contar como ingreso en el momento de la subasta. De todos modos, operar de una $\mathrm{u}$ otra forma hace variar muy poco el porcentaje de beneficio (de 37,24 a 38,20 ), que es el dato que nos interesa. Encontramos otros casos parecidos en los arrendamientos de la castellanía de Amposta. Para 1723 no existe más que una cuota general de gastos; hemos calculado para la primicia una cantidad aproximada a la media de los otros tres años.

${ }_{52} \mathrm{Si}$ descontásemos los gastos del molino harinero (como contrapartida mínima al hecho de que no figuren sus ingresos en el cargo), el beneficio ascendería a 7.689,19 ps. $(45,15$ por 100$)$.

${ }^{53}$ No se han deducido los gastos del molino por no haber tampoco ninguna partida de ingresos referente al mismo; los gastos globalizados de 1773 se han repartido proporcionalmente al conjunto de los demás años en los epígrafes «Salario, casa y gasto del colector» $(241,33$ ps.), «Recolección de frutos» $(143,22)$ y «Molino harinero» $(115,66)$. 
pocas cantidades que están indicadas pero no valoradas. Dado, además, que el arrendamiento era global, nos ha parecido obligatorio integrar las cuentas, aun a riesgo de dejar de lado las enseñanzas que podían desprenderse de un análisis más pormenorizado ${ }^{54}$.

Sumando los resultados de los diferentes pueblos tal y como aparecen en las cuentas y añadiendo el monto del arrendamiento, el resultado se salda con una pérdida de más de 1.500 ps. (cuadro 6). Sin embargo, sabemos que se obtuvo como mínimo un beneficio de $1.849,97$ ps., de acuerdo con la liquidación de cuentas pasada entre García i Alegre y Bover. Hay que tener en cuenta que existen partidas en blanco o que se dice que han sido cobradas directamente por los arrendatarios, que faltan las cuentas de Corbera de los años 1772 y 1773 (Corbera representa para 1770 y 1771 el 6,28 de los ingresos totales) y que quedaron gran cantidad de pagos pendientes: como mínimo, $1.469,21$ ps. ${ }^{55}$.

En los cuadros 7 y 8 figura nuestra reconstrucción de las cuentas del arrendamiento. En el cuadro 7 se ha realizado la distribución por pueblos, para poner de manifiesto la estimación de los resultados de Corbera; en el 8 la distribución es por partidas, para que sea comparable con los cuadros realizados para los demás arrendamientos. Para ello hemos añadido a los gastos el valor

\section{CUADRO 6}

\section{Resumen de las cuentas de la bailia de Miravet}

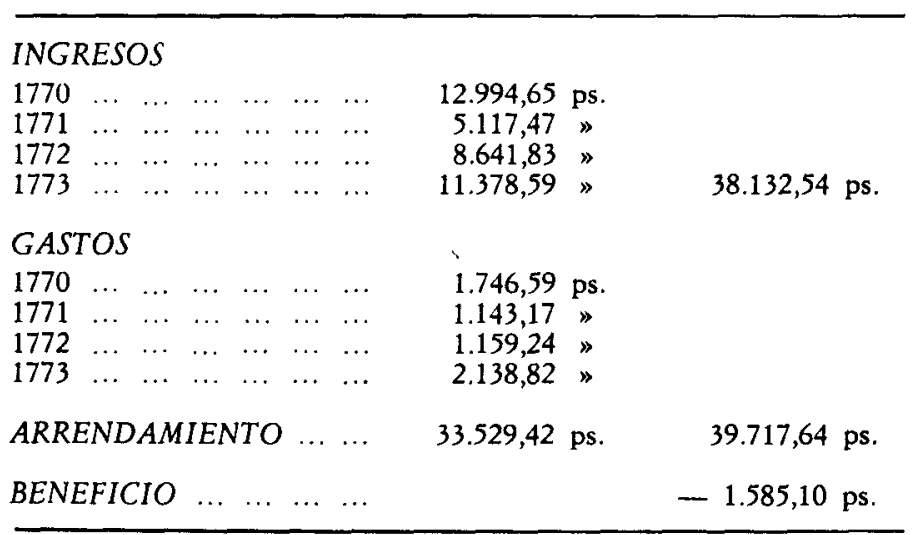

4 La base de los ingresos señoriales varía bastante de un lugar a otro, aunque casi en todas partes los cereales, y en especial el trigo, representan la parte principal de los in gresos. ravet.

${ }^{55}$ Principalmente por censos, hornos y barcajes de Benissanet, Pinell, Rasquera y $\mathrm{Mi}$ 


\section{CUADRO 7}

Cuentas estimadas del arrendamiento de la bailia de Miravet

\begin{tabular}{|c|c|c|c|c|c|}
\hline & 1770 & 1771 & 1772 & 1773 & Total \\
\hline \multicolumn{6}{|l|}{ INGRESOS } \\
\hline $\begin{array}{llllllll}\text { Batea } & \ldots & \ldots & \ldots & \ldots & \ldots & \ldots \\
\text { Corbera } & \ldots & \ldots & \ldots & \ldots & \ldots & \ldots \\
\text { Gandesa } & \ldots & \ldots & \ldots & \ldots & \ldots & \ldots \\
\text { Benissanet } & \ldots & \ldots & \ldots & \ldots & \ldots \\
\text { Pinell } & \ldots & \ldots & \ldots & \ldots & \ldots & \ldots \\
\text { Ginestar } & \ldots & \ldots & \ldots & \ldots & \ldots \\
\text { Rasquera } & \ldots & \ldots & \ldots & \ldots & \ldots & \ldots \\
\text { Miravet } & \ldots & \ldots & \ldots & \ldots & \ldots & \ldots & \ldots \\
\text { Miran } & & \ldots & \ldots & \ldots & \ldots & \ldots\end{array}$ & $\begin{array}{r}2.482,48 \\
1.818,84 \\
2.113,52 \\
2.848,46 \\
1.186,68 \\
822,10 \\
483,82 \\
986,34\end{array}$ & $\begin{array}{r}755,70 \\
1.172,08 \\
934,66 \\
685,14 \\
449,44 \\
194,03 \\
282,77 \\
782,47\end{array}$ & $\begin{array}{r}2.592,95 \\
1.809,41 \\
1.092,43 \\
2.150,96 \\
1.243,83 \\
627,85 \\
503,73 \\
867,29\end{array}$ & $\begin{array}{r}2.344,62 \\
2.072,70 \\
1.080,55 \\
2.509,56 \\
1.818,51 \\
1.077,82 \\
448,60 \\
1.120,24\end{array}$ & $\begin{array}{l}8.175,75 \\
6.873,03 \\
5.221,16 \\
8.194,12 \\
4.698,46 \\
2.721,80 \\
1.718,92 \\
3.756,58\end{array}$ \\
\hline Total $\ldots \ldots \ldots$ & $12.742,24$ & $5.256,15$ & $10.888,45$ & $12.472,84$ & $41.359,68$ \\
\hline \multicolumn{6}{|l|}{ GASTOS } \\
\hline 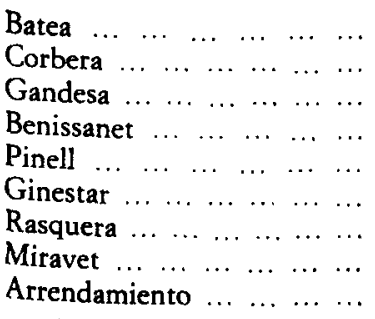 & $\begin{array}{r}234,24 \\
223,34 \\
191,29 \\
702,31 \\
310,96 \\
88,99 \\
87,93 \\
89,08 \\
8.381,33\end{array}$ & $\begin{array}{r}118,97 \\
102,31 \\
112,92 \\
644,56 \\
14,64 \\
17,67 \\
85,95 \\
61,13 \\
8.381,33\end{array}$ & $\begin{array}{r}156,33 \\
150,05 \\
116,96 \\
421,44 \\
387,07 \\
27,09 \\
87,93 \\
78,57 \\
8.381,33\end{array}$ & $\begin{array}{r}212,78 \\
259,63 \\
217,91 \\
921,53 \\
622,11 \\
39,77 \\
92,91 \\
99,82 \\
8.381,33\end{array}$ & $\begin{array}{r}722,32 \\
735,33 \\
639,08 \\
2.689,84 \\
1.334,78 \\
173,52 \\
354,72 \\
328,60 \\
33.525,32\end{array}$ \\
\hline Total $\ldots \ldots \ldots$ & $10.309,47$ & $9.539,48$ & $9.806,77$ & $10.847,79$ & $40.503,51$ \\
\hline BENEFICIO & & & & & 856,03 \\
\hline
\end{tabular}

de los cereales gastados en la almazara de el Pinell para la alimentación de los animales (se trata de un molino de sangre) y alguna pequeña cantidad cuya no aparición en las cuentas de un año solamente puede deberse a olvido, además de la estimación de los gastos de Corbera los años 1772 y 1773, que hemos calculado bajo la hipótesis de que en 1772 y 1773 los gastos de Corbera representaron sobre el total de los gastos la misma proporción que el promedio de los años 1770 y 1771 .

En los ingresos hemos añadido la estimación de Corbera, realizada bajo los mismos supuestos que para los gastos, y la estimación de aquellas partidas que no están valoradas, y que lo han sido a los precios más corrientes del mismo año; se trata principalmente de los cereales gastados en el molino de el Pinell y de partidas de vino o de aguardiente. El cálculo así reconstruido se 


\section{CUADRO 8}

Cuentas estimadas del arrendamiento de la bailia de Miravet

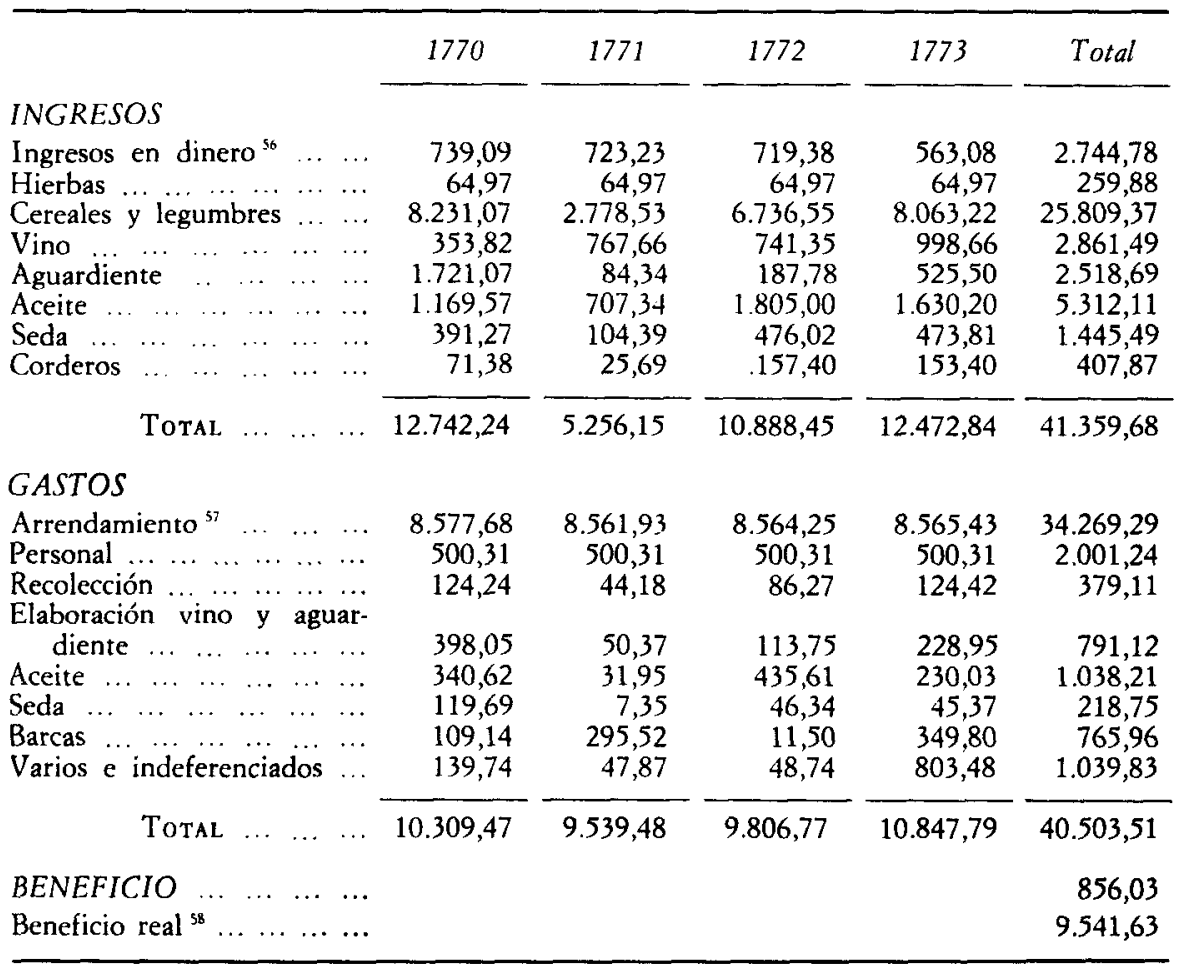

cierra con un superávit de 856,03 ps., bastante inferior al beneficio repartido $(1.849,97$ ps.). La diferencia tiene un factor en lo hipotético de nuestro cálculo de los ingresos y gastos de Corbera para 1772 y 1773, pero también existen otras dos posibles causas: entre 1773, que se cierran las cuentas, y 1781, que se lleva a cabo la liquidación con Bover, posiblemente se cobró una parte de las deudas pendientes ${ }^{59}, \mathrm{y}$, además, y con mayor probabilidad, los

"Censos, laudemios, «molinadas», barcajes y derechos varios.

"Arrendamiento y congrua a los priores, que consideramos como una partida más del arrendamiento, dado que eran unas cantidades fijas que, al obtener la subasta, ya se sabía que habría que pagar.

${ }_{58}$ De acuerdo con la liquidación entre García i Alegre y Bover.

"4 Las deudas que nos son conocidas ascendían, en 1773, a $1.469,21$ ps., correspondientes a censos (de particulares o de los pueblos), derechos de horno, diezmos menudos (que debían pagarse en algunos sitios en moneda) y barcajes de los pueblos de Benissanet, 
gastos que figuran realizados para mantener en funcionamiento las barcas de Benissanet y de Miravet no debían ser computados en realidad como tales gastos.

El por qué merece una explicación algo más detallada. La barca de Benissanet originó a lo largo de los cuatro años unos gastos de 695,41 ps., casi la mitad de los cuales ( 342,30 ps.) en 1773, año que se compró una gúmera nueva (o sea, la maroma que tendida de ribera a ribera guiaba el paso de la barca) y se repararon las dos barcas. A cambio, los arrendadores tenían derecho, por concepto de barcaje, a 214,1 ps., pero solamente consiguieron cobrar 163,41 ps. A finales de 1772 , la deuda ascendía a 114,14 ps.; es muy dudoso que ningún arrendatario hubiese emprendido reformas importantes el último año del arrendamiento si solamente podía esperar pérdidas y, además, tenía la excusa de que ni siquiera las insuficientes cantidades pactadas le eran satisfechas íntegramente. La barca de Miravet era menos costosa: solamente originó 70,55 ps. de gastos, pero sin que aparezca en las cuentas ingreso alguno por este concepto. La explicación de que los arrendatarios estuviesen dispuestos a realizar mejoras y reparaciones ha de buscarse o bien en el hecho de que la barca fuese objeto de un subarrendamiento particular, cuyo importe recibiesen directamente los arrendatarios sin pasar por manos del colector y sin dejar, por tanto, rastro en las cuentas, o bien que los arrendatarios actuasen como simples intermediarios, de manera que los gastos realizados en las barcas serían deducidos de los pagos de los arrendamientos. La obligación impuesta a los arrendatarios de cuidar y, en su caso, reparar los desperfectos del patrimonio señorial, con abono posterior de los gastos realizados, es una práctica que aparece repetidamente en los arrendamientos de la misma Orden de San Juan de Jerusalén en el Gran Priorato de Catalunya. Esta última posibilidad explicaría, mejor que ninguna otra, los gastos llevados a cabo en Benissanet el último año del arrendamiento.

De ser ciertas estas explicaciones, la deducción en los gastos elevaría el beneficio, según nuestros cálculos, a $1.548,47$ ps.; la diferencia con la cantidad realmente obtenida sería pequeña, 227,98 ps., fácilmente cargable a las

Pinell, Rasquera y Miravet; en la liquidación con Bover aparece una deuda de 264,23 ps. como censos dejados de cobrar de Gandesa y otros lugares y, además, se seguía un pleito con el Ayuntamiento de Gandesa por esta causa. El hecho de que el pleito fuese sola. mente con Gandesa hace suponer que la mayor parte de los $2.648,23$ ps. eran debidos por este pueblo; tampoco hay seguridad de que las deudas correspondan (o correspondan por entero) al período 1770-1773: aunque la partida figura a continuación de la correspondiente al repartimiento de beneficios de 1770-1773, los mismos arrendatarios ganaron también la subasta del período siguiente, que se saldó con pérdidas, por lo que no había lugar a una partida correspondiente a este periodo en la data. Es posible, por tanto, que una parte de los $1.469,21$ ps. de 1773 hubiese sido cobrada e incrementase la suma de los ingresos de 1770-1773 con posterioridad al cierre de las cuentas del arrendamiento. 
dos partidas antes mencionadas: diferencias en el beneficio de Corbera de 1772 y 1773 y cobro de parte de las deudas pendientes.

Para el cálculo de los porcentajes de beneficio hemos deducido de los gastos los costos ocasionados por las barcas y añadido a los ingresos la cantidad necesaria para igualar con ello los ingresos que sabemos realmente obtenidos. El resultado son $39.737,55$ ps. de gastos y $41.587,66$ de ingresos, lo que nos da un beneficio de $1.849,97$ ps. y un porcentaje de beneficio del 4,66 por 100 .

Nos encontramos, pues, ante una situación notablemente diferente a la que ofrecían los arrendamientos anteriores: la mala cosecha de 1771 pesa como una losa sobre los ingresos y prácticamente reduce a la nada los beneficios; cierto que quedaba una importante cantidad de deudas pendientes $y$, quizá por esta razón, los arrendatarios reincidieron en el cuatrienio siguiente, pero fue para su mal: lejos de resarcirse y cobrar las deudas, los arrendatarios de 1774 a 1777 tuvieron una pérdida de $2.593,96$ ps. ${ }^{60}$.

La desgracia de la compañía arrendataria es nuestra suerte porque nos permite observar los riesgos del negocio. En principio, estábamos tentados de afirmar que los socios podían atreverse a participar en negocios de arrendamiento siempre que dispusiesen de capital del primer año; pero el ejemplo de la bailía de Miravet muestra claramente que si los socios no hubiesen dispuesto más que del capital del primer año no habrían podido hacer frente a los plazos de 1771 ni de 1772: hasta 1773, con las buenas cosechas de este año, no se logró obtener beneficios. Sin embargo, también es cierto que a menudo los arrendadores soportaban retrasos en el cobro de los plazos cuando las cosechas resultaban inferiores a lo previsto; denunciar el arrendamiento por falta de pago era jurídicamente posible, pero arriesgado: los derechos quedaban sin colector legal mientras se procedía a una nueva subasta; ésta tendía a alcanzar cantidades más bajas que la anterior, si no quedaba desierta, y, además, podía resultar muy difícil recuperar los pagos pendientes si los arrendatarios eran denunciados

\section{CONCLUSIONES}

De la serie de arrendamientos estudiados (cuyo resumen puede verse en el cuadro 9) parece deducirse, en primer lugar, que los beneficios obtenidos (col. IV) podían ser, en los mejores casos, de la mitad del capital invertido, aunque quizá cabría considerar estos beneficios como excepcionales, lo mismo que los años saldados con pérdidas. De forma que podríamos pensar en unos

* Según las cuentas entre García i Alegre y Bover. También se saldó con pérdidas el arrendamiento de los mismos años de la Segarra (posiblemente, la encomienda de la Segarra de la misma Orden Militar de San Juan de Jerusalén). 


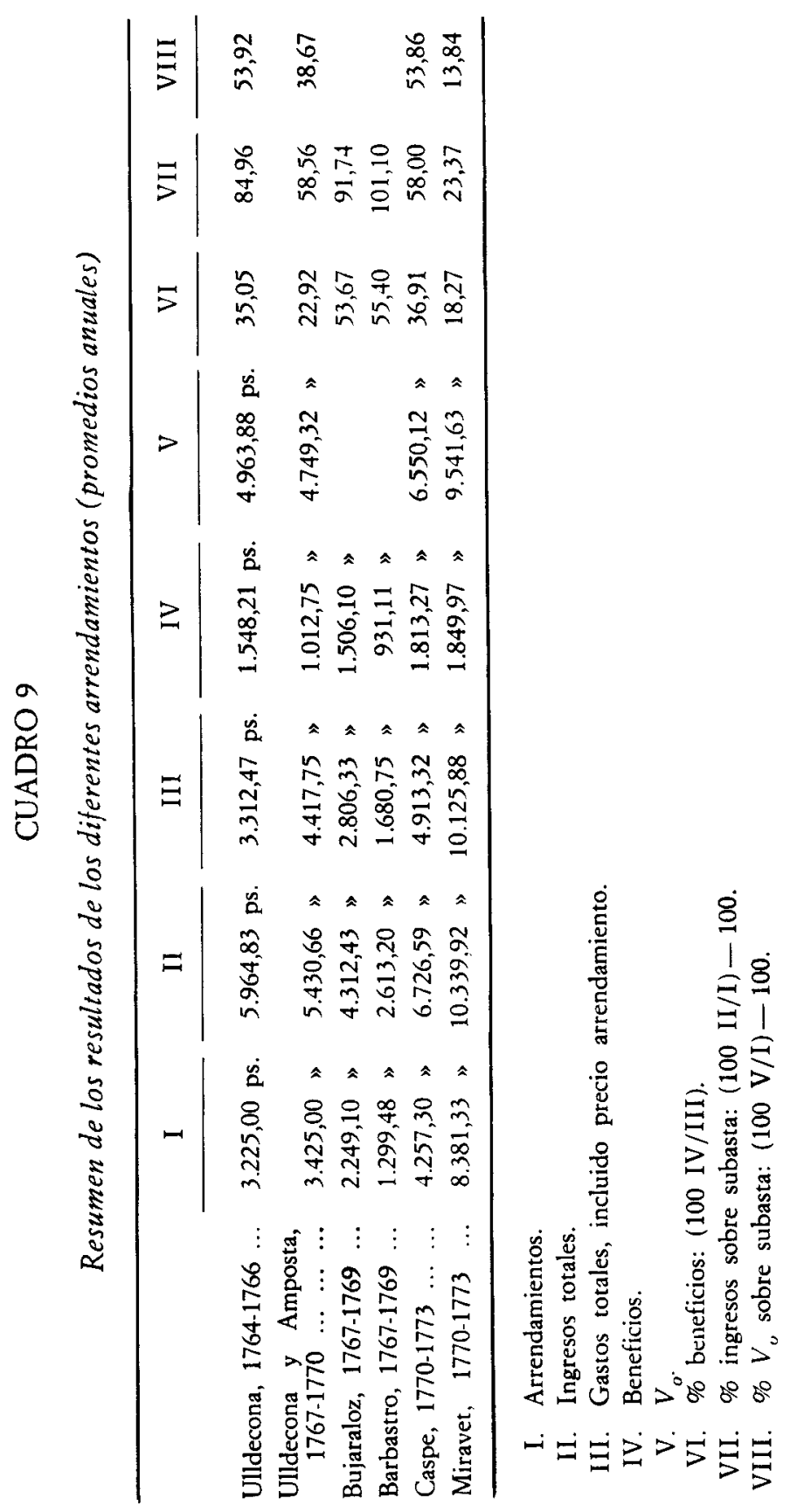


beneficios de aproximadamente un tercio (Ulldecona, 1764; Caspe) para los años buenos y de una quinta parte (Ulldecona y Amposta, 1767; Miravet) los años malos. De todos modos se trata, evidentemente, de una actividad sumamente remunerativa, aunque también arriesgada. Hemos añadido el cálculo de los ingresos sobre la subasta (col. VII) en un intento de dar alguna pista sobre los beneficios obtenibles, conocido el monto del arrendamiento. La dispersión resultante no parece ofrecer bases para realizar previsión alguna si no se conoce más que el montante de la subasta. El segundo punto que nos interesa, el valor original del producto extraído de las economías sometidas a señorío, parece que puede ser calculado entre el 40 y el 50 por 100 por encima del valor de la subasta para los años buenos y alrededor de un 15 por 100 para los años malos. Naturalmente, otra cosa es la incidencia de esta deducción sobre las economías campesinas: menores cantidades en años malos pueden representar punciones más graves sobre la renta familiar, de manera que podemos considerar que esta deducción tiende a ser una constante, con tendencia a crecer, a resultar más gravosa,cuando el porcentaje es excepcionalmente bajo.

Obteniendo de los pueblos un valor de un 40.50 por 100 superior al ofrecido en la subasta, los arrendamientos podían alcanzar en los años buenos unos beneficios sobre el capital invertido (arrendamiento más gastos) del orden de un 35 por 100; algo más si tenemos en cuenta que el capital invertido era menor, dado que muchos gastos se pagaban con los ingresos que se iban obteniendo. En años malos, el valor extraído podía oscilar sobre un 15 por 100 más de lo ofrecido en la subasta, y los beneficios entre un 15 y un 20 por 100 . Pero para los miembros más activos de las compañías el beneficio podía ser bastante mayor, tanto a consecuencia de los salarios obtenidos al servicio de la compañía como por la compra a ésta y posterior comercialización particular de parte de los productos.

\section{A MODO DE APENDICE: EL NEGOCIO DEL AGUARDIENTE}

Ya hemos indicado que la mayor parte del producto obtenido por los arrendatarios era objeto de transformación antes de su comercialización, pero que para la mayoría de los productos resulta imposible cualquier cálculo sobre el valor añadido por estas transformaciones. Solamente en el caso del aguardiente, y a condición de olvidarnos de que la materia prima para su obtención es ya un producto transformado, el vino, podemos intentar una cierta aproximación, puesto que conocemos los precios del vino y del aguardiente $\mathrm{y}$ los gastos de transformación.

A pesar de ello, el cálculo ha de basarse en' algunas asunciones para suplir los datos inciertos. En primer lugar, hemos considerado que se trata de aguar- 
diente refinado o a prueba de aceite, dado que los precios obtenidos son muy parejos a los que encontramos para estos mismos años en los libros de la casa "Prat, Martí, Baldrich i Fuster", de Reus ${ }^{61}$; en segundo lugar, hemos aceptado para este aguardiente a prueba de aceite un rendimiento de una unidad de aguardiente por cada cuatro de vino corriente ${ }^{62}$. Naturalmente, el rendimiento variaba según la calidad del vino y, posiblemente, era del 1 por 6 para los vinos más flojos; pero en este caso también era menor el precio del vino: en 1770 , mientras el vino de Gandesa se vendió a 3,86 y a 4,5 ps. la carga, el vino comprado en Batea para hacer aguardiente lo fue a menos de la mitad de este precio, a 1,61 ps. De manera que podemos considerar que la baja del precio se compensa con el menor rendimiento.

A partir de estas premisas aparece una notable correlación entre el precio del vino y el del aguardiente y entre los precios de la bailía, los de Reus (para el aguardiente) ${ }^{63}$ y los de Barcelona (para el vino), tal como puede verse en el cuadro 10. La única discordancia aparece en el precio del vino de Barcelona de 1773, que se separa con exceso de la evolución de los datos en las tres columnas restantes, sin que hayamos podido encontrar explicación alguna a este hecho.

Con estos datos y los que nos ofrecen las cuentas de los arrendamientos podemos calcular, aproximadamente, el valor del aguardiente vendido ${ }^{64} \mathrm{y}$ la ganancia obtenida por los arrendatarios al realizar la operación. Por lo que respecta al $V_{a}$, los cálculos pueden verse en el cuadro 11 .

Las ganancias de los arrendatarios no son, evidentemente, estos 524,29 ps., puesto que la elaboración del aguardiente supone importantes gastos, muchos de los cuales no encontramos contabilizados (jornales) o, al menos, no lo están

" Olivé (1983). Precisamente García i Alegre y Bover habian invertido en la creación de una sucursal de esta misma casa en la Habana, por lo que es muy probable que hubiesen efectuado también con ellos negocios de aguardiente.

* Según el Diccionario de Ronquillo, «los vinos destilados en aguardiente se reducían a un tercio de volumen" - Torras (1976), p. 49-, pero debía tratarse del aguardiente a prueba de Holanda. Pero tanto la comparación de los precios como una única mención en la liquidación de cuentas entre García i Alegre y Bover nos indica que el obtenido en la bailía era refinado o «a prueba de aceite». Ahora bien, Pierre Vilar (1962), vol. III, p. 435 , indica que la relación en grado entre el aguardiente a prueba de aceite y el aguardiente a prueba de Holanda era de un 73 por 100, por lo que en este caso necesitaban cuatro cargas de vino para obtener una de aguardiente.

${ }^{63}$ Hay que tener en cuenta que los precios de la bailía son precios puntuales, de una 0 unas pocas ventas, mientras que los precios de Reus son medias anuales. Examinando las medias mensuales de Reus, los precios de la bailía se sitúan cerca de los precios más altos, e incluso algún año los superan.

${ }^{64}$ Estos cálculos modificarían el $V_{0}$ de la bailía de Miravet, pero en un porcentaje tan pequeño que no hemos creído conveniente introducir esta corrección, al no poderse hacer más que para un producto y un arrendamiento. En todo caso, la diferencia es de un solo punto: la cifra de la columna VII del cuadro 9 pasaría a ser 12,85 , en vez de los 13,84 que en ella figuran. 


\section{CUADRO 10}

Precios del vino y del aguardiente en la bailia de Miravet, comparados con los precios del aguardiente en Reus y los del vino en Barcelona

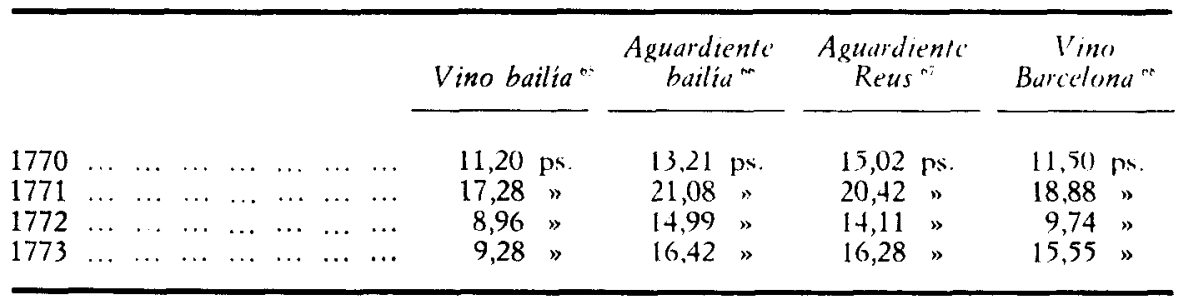

\section{CUADRO 11}

Valor en vino del aguardiente vendido

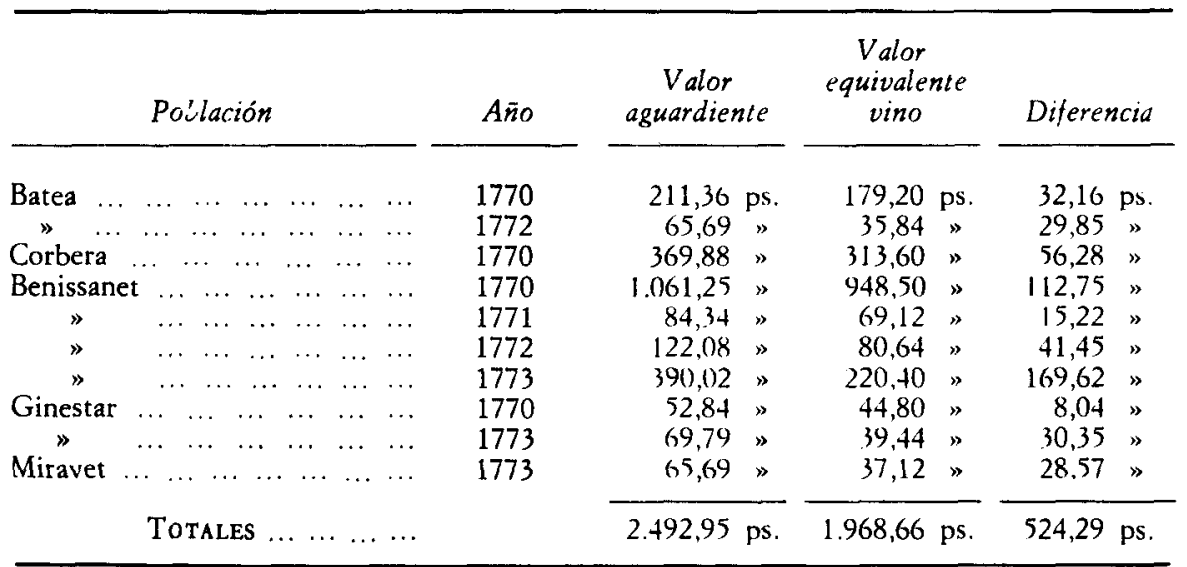

${ }^{\circ 5}$ Promedio de los precios citados en el arrendamiento, a excepción del vino que consta comprado para convertirlo en aguardiente. En ps, por cuatro cargas (para facilitar la comparación con la carga de aguardiente).

${ }^{60}$ Medida de los precios de venta obtenidos en ps. por carga. Cuando se hace mención de precio por bota se ha considerado ésta de cuatro cargas.

${ }^{67}$ Precio medio del aguardiente a prueba de aceite, según los datos publicados por Olivé (1983), considerando los años a partir de la vendimia, o sea, de octubre a septiembre.

*egún Vilar (1962), vol. III, p. 372, en pesos por cuatro cargas, pero iniciando cada año en el cuarto trimestre, o sea, a pattir de la vendimia. Con ello se marcan mejor las tendencias y las cifras resultan más concordantes con las obtenidas en la bailía. 
siempre (leña, fabricación de botas, transporte, «manifestación»), por to que nuestro cálculo ha de pecar por defecto. Los gastos contabilizados ${ }^{69}$ ascienden a 441,33 ps.; los beneficios han de ser considerados como pobres: 82,96 ps.; si tenemos en cuenta el capital invertido (valor del vino más gastos de elaboración y transporte), el beneficio es del 3,44 por 100 , beneficio que posiblemente quedaría reducido a cero si las cuentas de gastos fuesen más completas. ¿Hemos de concluir que no había beneficio en la elaboración del aguardiente? No tendría sentido; pero este beneficio parece obtenerse de la posibilidad de destilar vinos de baja calidad (y posiblemente la mezcla de partidas y calidades de las que obtenían su vino los arrendatarios no ayudaba a obtener buenos caldos) y también del ahorro en el transporte. Podría objetarse que el vino consta siempre como vendido en el lugar; pero faltaría saber si habría existido igualmente ( $\mathrm{o}$ al mismo precio) la posibilidad de dar salida a cantidades mayores o a calidades menores. Hay un tercer factor que podría tenerse en cuenta: el beneficio particular de los principales arrendatarios; sabemos que García i Alegre y Bover enviaron botas de aguardiente a la Habana, aunque ignoramos en qué año lo hicieron. Las cinco botas de Bover, adquiridas a un precio mucho más bajo que el de los años del arrendamiento, 8,45 ps. la carga, valían 169 ps. y produjeron un beneficio de 29,14 ps., o sea, del 17,24 por 100; aun sin obtener beneficios directos aparentes, los socios más activos de las compañías arrendatarias podían estar, pues, vivamente interesados en la obtención de aguardiente.

${ }^{\circ y}$ En Corbera, en 1770, los gastos de vendimia y fabricación del aguardiente van unidos. Los hemos añadido íntegros a esta suma, puesto que son muy superiores, sin duda, los gastos no contabilizados. 


\section{BIBLIOGRAFIA}

Canales, Esteban (1982): «Los diezmos en su etapa final», en La economia española al tinal del Antiguo Régimen, I: «Agricultura», edición e introducción de Gonzalo Anes, Madrid, Alianza Editorial.

Fontana Lázaro, José (1974): "Comercio colonial e industrialización: una reflexión sobre los orígenes de la industria moderna en Catalunya», en Jordi Nadal y Gabriel Tortella (eds.): Agricultura, comercio colonial y crecimiento económico en la España contemporánea, Barcelona, Ed. Ariel.

Hernández Esteve, Esteban (1983): «Situación actual de la Historia de la Contabilidad en la España del Antiguo Régimen», en Banco de España: Actas del Primer Congreso sobre archivos económicos de entidades privadas, 3.4 junio 1982, Madrid, Banco de España.

OLIVÉ I OlLÉ, Francesc (1983): «Una aportació a l'estudi del comerç de l'aiguardent a finals del segle xviII: la companyia "Prat, Martí, Baldrich i Fuster"», en L. J. Navarro (coord.): Siglo XVIII. Una aproximación interdisciplinar, Tarragona, Facultad de Geografía e Historia.

SALES, Núria (1983): «Ramblers, traginers i mules», Recerques, núm. 13, pp. 65-81.

Torras, Jaume (1976): «Aguardiente y crisis rural. Sobre la coyuntura vitícola, 1793 . 1832», Investigaciones Económtcas, núm. 1, pp. 45-67.

Torras Elías, Jaume (1979): "Sobre la renta señorial en Catalunya a finales del siglo xvin», en ANEs, G., et al.: La economia agraria en la bistoria de España. Propiedad, explotación, comercialización y renias, Madrid, Ed. Alfaguara.

VILAR, Pierre (1962): La Catalogne dans l'Espagne Moderne, 3 vols., París, SEVPEN. 